\title{
Effects of truck traffic on top-down fatigue cracking performance of flexible pavements using a new mechanics-based analysis framework
}

\author{
Yared H. Dinegdae ${ }^{1} \&$ Björn Birgisson ${ }^{1,2}$ \\ ${ }^{1}$ Division of Soil and Rock Mechanics, KTH Royal Institute of Technology, \\ Stockholm, Sweden \\ ${ }^{1,2}$ School of Engineering and Applied Science, Aston University, Aston Triangle, \\ Birmingham B4 7ET, UK
}

\begin{abstract}
The mechanics-based analysis framework predicts top-down fatigue cracking initiation time in asphalt concrete pavements by utilizing fracture mechanics and mixture morphology-based property. To reduce the level of complexity involved, traffic data was characterized and incorporated into the framework using the equivalent single axle load (ESAL) approach. There is a concern that this kind of simplistic traffic characterization might result in erroneous performance predictions and pavement structural designs. This paper integrates axle load spectra and other traffic characterization parameters into the mechanics-based analysis framework and studies the impact these traffic characterization parameters have on predicted fatigue cracking performance. The traffic characterization inputs studied are traffic growth rate, axle load spectra, lateral wheel wander and volume adjustment factors. For this purpose, a traffic integration approach which incorporates Monte Carlo simulation and representative traffic characterization inputs was developed. The significance of these traffic characterization parameters was established by evaluating a number of field pavement sections. It is evident from the results that all the traffic characterization parameters except truck wheel wander have been observed to have significant influence on predicted top-down fatigue cracking performance.
\end{abstract}

Keywords: mechanics-based, fatigue, ESALs, axle load spectra, asphalt pavement, Monte-Carlo 


\section{Introduction}

Load induced top-down fatigue cracking is one of the dominant failure modes of flexible pavements. There are a number of mechanistic empirical (M-E) methods which can be used to evaluate and design asphalt concrete pavements for this kind of distress (Dinegdae \& Birgisson, 2015; Dinegdae, Onifade, Jelagin \& Birgisson, 2015; NCHRP, 2010; Wang, Birgisson \& Roque, 2007). One of these methods is the mechanics-based analysis and design framework. This framework predicts crack initiation time in asphalt concrete pavements by utilizing hot mix asphalt fracture mechanics (HMA-FM), and asphalt mixture morphology-based material property predictive models (Dinegdae et al., 2015). The mechanics-based analysis framework has been calibrated and validated for Florida conditions using field pavement sections that have a wide range in design inputs and functional requirements. The calibrated framework has been shown to be successful in predicting crack initiation times that correspond well with observed cracking performances in the field. However, to reduce the level of complexity involved, traffic loading, which was identified by Wang and Liu (2000) to be a primary factor in causing top-down fatigue cracking, was characterized and incorporated into the mechanics-based analysis framework and other similar analysis methods in a way that did not consider recent advancements in truck traffic characterizations. Accordingly, the mechanics-based analysis framework adopted the equivalent single axle load (ESAL) approach for characterizing expected traffic and consequently, the traffic of the coring year was aggregated into ESALs and applied to the whole analysis period. This way of simplistic traffic characterization might introduce uncertainty into the predictions as many traffic characterization parameters that might have an effect on top-down fatigue cracking performance are ignored.

The ESALs concept has its origin in the1950s American Association of State Highway Officials (AASHO) road test, and has been since the basis for many pavement design procedures, including the American Association of State Highway and Transport Officials (AASHTO) pavement design guide (AASHO, 1962; AASHTO, 1993). The ESALs approach of traffic characterization is based on the concept of equivalent axle load factor (EALF). An axle EALF indicates the damage a particular axle load and axle configuration induces relative to a standard axle load and its magnitude depends on pavement type, thickness and terminal failure conditions. Based on empirically developed equations and experience, the AASHTO design procedure has developed a set of EALFs for different pavement types and axle configurations (AASHTO, 1972). This way of converting a mixed traffic into ESALs using empirically derived EALFs may not be suitable for design scenarios which are different from the original conditions upon which the performance observations were made. Moreover, the ESALs approach of converting a mixed traffic stream into one design traffic number does not utilize available traffic data sufficiently, which makes it inconsistent with the state of the practice method for traffic monitoring as outline in the Traffic Monitoring Guide (FHWA, 2001). Findings from various studies have shown that the use of ESALs to represent actual traffic can limit the accuracy of pavement design. To improve the existing limitations of the ESALs approach, these studies recommend a pavement 
design based on actual axle load statistics and vehicle classification data (Hajek, 1995; Rauhut, Lytton \& Darter, 1984).

A comprehensive traffic characterization approach that reflects accurately the diverse effect traffic loads have on pavement performance is needed in order to accurately determine pavement response and damage accumulation. For this purpose, the mechanistic empirical pavement design guide (MEPDG) and other M-E design approaches characterize expected traffic loads with inputs which require the magnitude, configuration and frequency of axle loads (MnPAVE, 2005; NCHRP, 2004; Timm \& Young, 2004). Instead of aggregating the whole traffic into ESALs, these design procedures apply a more precise traffic characterization approach that directly uses the entire axle load distributions. By characterizing the traffic in this manner, these methods compute the pavement response and damage accumulation from each axle type and load applications, and eventually predict load-related distresses for both new and rehabilitated pavements. Moreover, this way of traffic characterization creates the opportunity for assessing the impact of various traffic characterization parameters such as traffic growth rate, volume adjustment factors and lateral wheel wander on predicted performance (NCHRP, 2004).

The purpose of this paper is to integrate axle load spectra into the mechanics-based analysis framework and to establish the impact various traffic characterization parameters such as vehicle class distribution, traffic seasonal variation, traffic growth rate and lateral wheel wander have on predicted fatigue cracking performance. Establishing the significance of these parameters may aid researchers and pavement practitioners to focus on those inputs which have been found to have the most effect on predicted performance. For this purpose, a traffic integration approach which includes all the traffic characterization parameters and Monte Carlo simulation for lateral wheel wander was proposed. In addition, traffic characterization inputs such as vehicle class distribution, axle load spectra, and volume adjustment factors were developed for Florida conditions using representative database. The significance of each traffic characterization parameter was established by evaluating a number of field pavement sections with the mechanicsbased analysis framework.

\section{Mechanics-based analysis framework}

The mechanics-based analysis framework predicts top-down fatigue cracking initiation (CI) time in asphalt concrete pavements through mechanistic-empirical principles. The framework was developed on the basis of hot mix asphalt fracture mechanics (HMA-FM), and considers effects of factors such as mixture aging and healing on predicted fatigue cracking performance. Asphalt mixture morphology-based models were developed and incorporated into the framework so as to predict the evolution in key material properties with age (Dinegdae et al., 2015). The framework has been calibrated and validated for Florida conditions using field pavement sections that have a wide range in input parameters, and which encompass the functional requirements that exist in practice. The calibrated framework has been found to be successful in predicting crack initiation times that correspond well with observed performances in the field. The analysis framework was 
extended further into a reliability-based design framework, which can be used to optimize pavement sections for top-down fatigue cracking (Dinegdae \& Birgisson, 2015). The general outline of the mechanics-based analysis framework is presented in Figure 1. The analysis framework has five main components which are the inputs module, material property predictive model, pavement response model, damage computation and recovery model and crack initiation evaluation model. The detail description of the five main components of the analysis framework is provided in the subsequent sections.

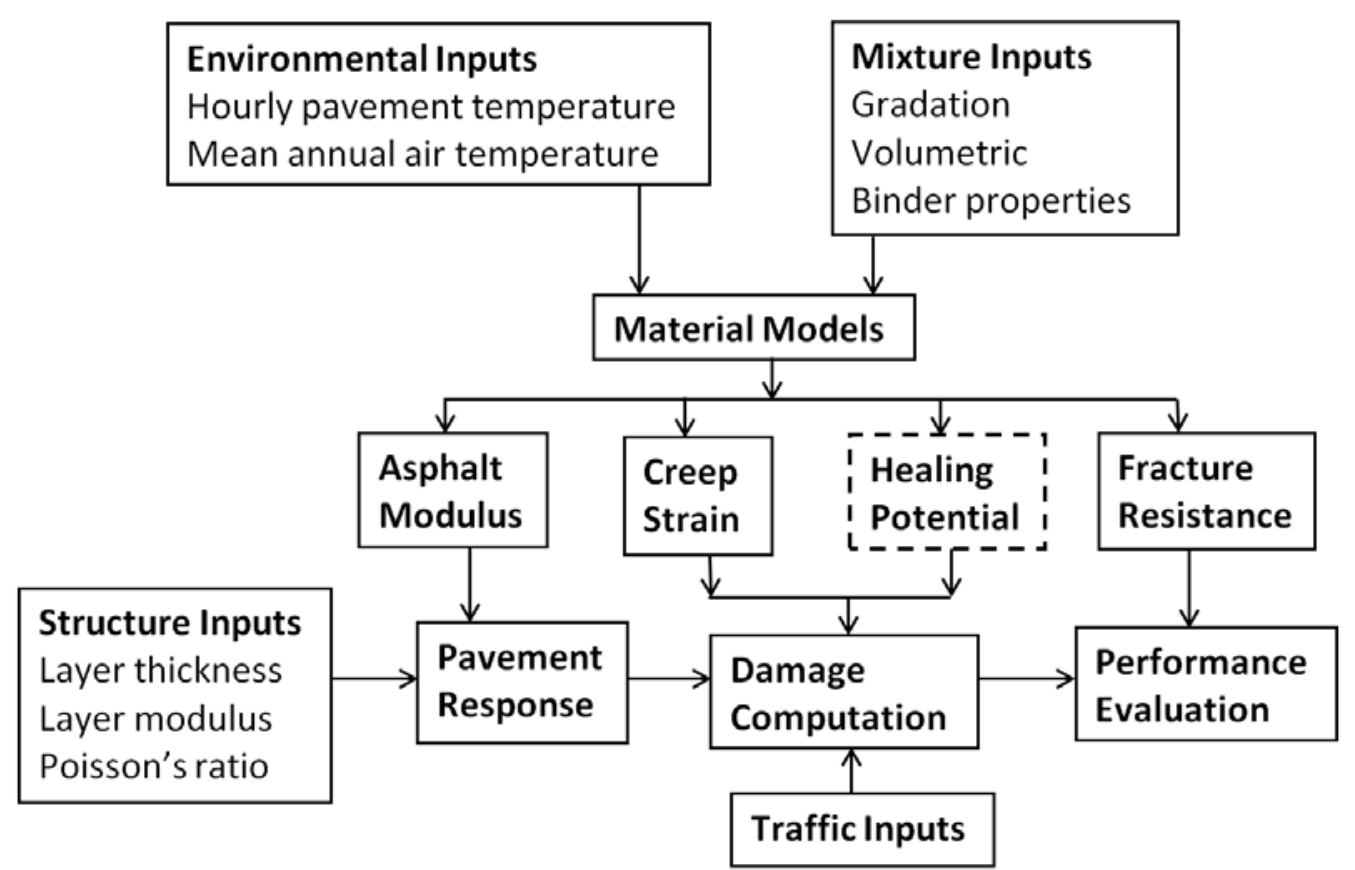

Figure 1. Flowchart for the mechanics-based analysis framework

\subsection{Inputs module}

As can be seen in Figure 1, the mechanics based analysis framework through its inputs module accounts for material properties and design parameters which are necessary for the performance evaluation of pavement sections for top-down fatigue cracking. The full gradation, volumetric and binder characterization inputs of asphalt mixtures are required to estimate asphalt concrete (AC) layer properties such as asphalt modulus $\left(E^{*}\right)$, creep strain $\left(\varepsilon_{p}\right)$, healing potential $\left(h_{y m}\right)$ and facture resistance $\left(D C S E_{\text {lim }}\right)$. The annual hourly air temperature and the mean annual air temperature (maat) are the environmental inputs which are required to determine the change in AC properties due to fluctuation in pavement temperature and aging. The hourly temperature profile at different depths in the AC layer was obtained by using a temperature predictive model developed by Viljoen (2001), which takes as an input a five year average annual hourly temperature data from the nearest weather station. The global aging model, which was developed by Mirza and Witczak (1995), was used in the analysis framework to account for the oxidative aging effect of the binder on the asphalt dynamic modulus and creep strain properties. Traffic and 
structural inputs such as hourly ESALs volume, tire inflation pressure, layer thickness, unbound layers modulus and Poison's ratio are also required for pavement response and damage computation analyses.

\subsection{Material property predictive models}

The material property predictive component of the analysis framework predicts the evolution in key damage and fracture properties such as asphalt modulus, creep strain, healing potential and fracture resistance. These predictive models capture the hourly and yearly change in these material properties which is mainly due to aging and fluctuation in pavement temperature. In the absence of laboratory based values, these predictive models provide the necessary inputs which are required for pavement response calculation and damage accumulation and recovery computation. The material property predictive models which are incorporated into the analysis framework are presented below.

\subsubsection{Asphalt stiffness aging model}

The asphalt stiffness aging model predicts the hourly dynamic modulus values of the AC layer. The model considers the stiffness gradient within the AC layer which is induced by temperature fluctuation and aging by calculating the dynamic modulus at different sub-layers within the AC layer. The analysis framework uses an empirical asphalt stiffness aging model which was developed for the NCHRP (2010) project. This empirical aging model was developed on the basis of the Witczak and Fonseca (1996) dynamic modulus master curve equation and estimates the hourly dynamic modulus values of each sub-layer using the corresponding hourly pavement temperatures. The asphalt stiffness aging model, as can be seen in Equation 1, incorporates an aging factor which is estimated by using the aged and unaged binder viscosities.

$$
\left|E^{*}\right|_{t}=\left|E^{*}\right|_{o} \frac{\log \eta_{t}}{\log \eta_{o}}
$$

where $\left|E^{*}\right|_{\mathrm{t}}$ and $\left|E^{*}\right|_{\mathrm{o}}$ are aged and original conditions dynamic modulus values respectively, which are estimated using a loading time of $0.1 \mathrm{~s}$. The binder viscosities at aged $\left(\eta_{t}\right)$ and unaged $\left(\eta_{o}\right)$ conditions are estimated at a reference temperature of $10^{\circ} \mathrm{C}$.

\subsubsection{Asphalt creep strain model}

The asphalt creep strain model predicts the near surface hourly creep strain $\left(\varepsilon_{p, \text { max }}\right)$ values of the AC layer which is induced by aging and fluctuation in temperature. The asphalt creep strain model, as can be seen in Equation 2, was developed using the creep compliance power law parameters $\left(m, D_{1}\right)$ and a loading time of 1000 s. Empirical equations which were developed using the asphalt master curve were used to estimate the creep compliance power law parameters in Equation 2 (Birgisson, Wang \& Roque, 2006).

$$
\varepsilon_{p, \max }=D_{1} \cdot m \cdot t^{(m-1)}
$$




\subsubsection{Dissipated creep strain energy limit model}

The dissipated creep strain energy limit $\left(D C S E_{\text {lim }}\right)$ model predicts the near surface yearly $D C S E_{\text {lim }}$ values of the AC layer. The $D C S E_{\text {lim }}$ is the limit or threshold energy which governs the fracture resistance of asphalt mixtures and can be obtained from the SuperPave indirect tension test (IDT) by deducting the elastic energy ( $E E$ ) from the fracture energy ( $F E$ ). An asphalt mixture morphology-based $D C S E_{\text {lim }}$ model was developed for the mechanics-based analysis framework through empirical analysis. The model characterizes mixture morphology using the primary structure $(P S)$ coating thickness $\left(t_{p}\right)$, which is the mastic thickness that coats the primary structure or the load bearing part of the aggregate. The PS coating thickness ( $t p)$ is calculated using the primary structure coordination number and the mixture porosity. These two parameters are determined using a morphological framework that is developed on the basis of aggregate packing arrangements and aggregate gradation interactions (Lira, Jelagin \& Birgisson, 2012; Yideti, Birgisson, Jelagin \& Guarin, 2013). The PS coating thickness $\left(t_{p}\right)$ by controlling the sizes and interconnectivity of pores can have a significant influence on aggregate interlock, stress transfer between aggregates and mixture performance (Kumar Das, Birgisson, Jelagin \& Kringos, 2013). Dinegdae et al. (2015) have also demonstrated using laboratory obtained DCSE $E_{\text {lim }}$ results that the PS coating thickness can influence mixtures DCSE $E_{\text {lim }}$ values.

The developed $D C S E_{\text {lim }}$ model has been found successful in delivering predictions which are in good agreement with experimental values (Dinegdae et al., 2015). As can be seen in Equation 3, $D C S E_{\text {lim }}$ has an inverse relation with both time and primary structure coating thickness.

$$
D C S E_{\lim }=k_{1}\left(\mathrm{t}_{p}\right)^{-k_{2}(\mathrm{t})^{-\left(k_{3}+k_{4} \cdot \log \left(\mathrm{t}_{p}\right)\right)}}
$$

where $k_{1}=2.38, k_{2}=0.79, k_{3}=0.33$ and $k_{4}=0.12$

\subsubsection{Healing potential model}

The mechanics bases analysis framework recognizes the importance of accounting for healing recovery as asphalt mixtures have the capacity to heal induced damage when subjected to favorable temperature conditions and rest periods between successive load applications (Button, Little, Kim \& Ahmed, 1987; Daniel \& Kim, 2001). A simplified healing potential $\left(h_{y m}\right)$ equation that considers mixture morphology and initial level of $D C S E_{\text {lim }}$ was used in the analysis framework to predict the near surface yearly healing potential of asphalt mixtures. The healing potential model was used to calibrate the analysis framework and for that reason an aging factor, $k$ that determines the healing potential trend of mixtures was introduced in the model. Equation 4 presents the healing potential model used in the analysis framework.

$$
h_{y m}(t)=1-\left(\left[\exp \left(\frac{t_{p}}{t}\right)^{-D C S E_{i}}\right]_{\text {norm }}\right)^{k}
$$


In Equation 4, a 50 year interval was suggested to normalize the equation which makes it to vary between 0 and 1 during the analysis period. The healing potential equation was used to calibrate the analysis framework and the aging parameter $k$ used in Equation 4 was replaced by the expression $15.5 \cdot t_{p}+3.35$ in the final model.

\subsection{Pavement response model}

The pavement response model computes the stress, strain and deformation in the pavement system for the prevailing environmental and material conditions as a result of traffic loading application. A multi-layered elastic analysis (MLEA) was used in the framework to obtain bending induced maximum surface tensile stress as bending is considered to govern the mechanism for top-down fatigue crack initiation in thin to medium AC layer thickness pavements (NCHRP, 2010). The MLEA assumes an axisymmetric geometry with linear elastic material behaviour for all the layers. The Young modulus $(E)$ and Poisson's ratio $(v)$ of each layer material is used to model the linear elastic response behaviour of the pavement system. The MLEA was used primarily for predicting the stress distribution on the AC surface and for a small strain problem where stress relaxation is allowed between loading events the difference between the stress distribution predicting by LEA and viscoelastic analysis is minimal. Pavement response analysis was performed using an $80 \mathrm{kN}$ single axle load with a tyre inflation pressure of $689 \mathrm{kPa}$, which is considered to be representative of the mixed traffic NCHRP (2010).

\subsection{Damage accumulation and recovery model}

According to HMA-FM, damage due to the repeated application of traffic loading is accumulated in the form of dissipated creep strain energy. The damage accumulation and recovery model computes the cumulative dissipated creep strain energy (DCSE $E_{a c u m}$ ) which is induced by the repeated application of traffic loading while taking into account healing recovery. The model computes damage on hourly basis by considering the traffic volume (ESAL), maximum surface tensile stress $\left(\sigma_{a v}\right)$, creep strain and healing potential. Equation 5 presents the damage accumulation and recovery equation used in the analysis framework.

$$
\operatorname{DCSE}_{\mathrm{acum}}=0.05 \cdot \sum_{i=1}^{\text {nhrs }} E S A L_{i} \cdot \varepsilon_{p, \max _{i}} \cdot \sigma_{a v_{i}}^{2}\left(1-h e_{i}\right)
$$

The damage estimation as can be seen in Equation 5 involves many design inputs and factors. Not to complicate the computation process further, Dinegdae et al. (2015) used the ESALs approach to characterize and incorporate expected traffic effect into the analysis framework. The coring year traffic was translated into ESALs and applied to the whole analysis period disregarding effects of axle load variations, traffic growth rate, lateral wheel wander and traffic volume adjustment factors on predicted fatigue cracking performance. 


\subsection{CI prediction model}

The mechanics-based analysis framework uses two energy-based parameters to determine fatigue cracking initiation time in AC pavements. Fracture mechanics specifies that fatigue crack initiates or propagates under specific loading, environmental, aging and healing conditions that are critical enough to exceed the mixture threshold energy. This critical condition is achieved when the accumulated dissipated creep strain energy after considering healing exceeds the limit dissipated creep strain energy of the mixture (Roque, Birgisson, Sangpetngam \& Zhang, 2002). Equation 6 presents the crack initiation prediction model used in the analysis framework.

$$
C I(t)=D C S E_{\text {lim }}(t)-D C S E_{\text {acum }}(t)
$$

\section{Traffic inputs characterization}

The traffic inputs which are required for characterizing truck traffic can be grouped into three main categories: vehicle volume data, vehicle classification data and axle weight data (NCHRP, 2004). Accurate characterization of traffic data is important for achieving a reliable pavement performance prediction and an optimized pavement structure. More emphasis should be given to those parameters which have been found to have a significant influence on pavement performance, and according to Swan, Tardif, Hajek and Hein (2008) the most significant factors affecting pavement performance are volume and type of trucks and axle load distribution factors. Accordingly, design methods like the MEPDG recommend a hierarchical approach for obtaining design inputs that can be used for the analysis and design of new and rehabilitated pavements. Based on availability of resources and criticality of the project, the MEPDG defines three broad levels of inputs: Level 1 through 3 (NCHRP, 2004).

As the mechanics-based analysis framework uses material property predictive models to determine the evolution in key material properties due to aging, it is generally considered to be appropriate for a Level 3 analysis and design of pavements. Level 3 analyses where traffic, materials and environmental inputs are typically obtained by averaging regional or state-wide representative values is considered to provide the lowest level of accuracy. Thus, Level 3 traffic characterization inputs which are representative of Florida conditions are required. These inputs should include among others vehicle class distribution, axle load spectra for each axle configuration and vehicle class, volume adjustment factors and numbers of axle per truck. Data from various sources, including the long term pavement performance (LTPP) database and publications from the Florida State University were used for developing the required traffic inputs (Cunagin, Reel, Ghanim, Roark \& Leggett, 2013; Kwigizile, 2004; NCHRP, 1999).

\subsection{Vehicle class distribution}

Vehicle class distribution represents the normalized annual percentage of each truck class within the annual average daily truck traffic (AADTT). The FHWA categorizes expected traffic volume 
with 13 types of vehicle classes and for pavement performance evaluation inputs from only vehicle class 4-13 are required as it is generally assumed that passenger cars induce negligible damage (NCHRP, 2004). As vehicle class compositions of a given highway depend on functional requirements and local economy, separate vehicle class distribution factors which are representative of Florida interstate and state road conditions were developed using Weigh in motion (WIM) data from NCHRP (1999) and Kwigizile (2004).

Eight vehicle class distribution WIM data from NCHRP (1999), which was part of the LTPP study, was included in this study. The average value for the WIM sites were developed using traffic data collected between two and five years. Even if this represents a relatively short period of time, for most of the sites the annual normalized truck class composition was not observed to change over time (NCHRP, 1999). Additional seven vehicle class distribution WIM data was used in this study from a study undertaken by Kwigizile (2004). Kwigizile (2004) collected vehicle class distribution data from WIM sites which were recently calibrated and located on major rural highways. Three days of vehicle class composition data was collected at each WIM site in a one month period, which was later averaged to obtain vehicle class composition factors for the studied highways. Kwigizile (2004) observed that the vehicle class distribution data for a given WIM site was not observed to vary on daily basis but there was substantial variation among the different WIM sites. The vehicle classification data from the two sources was organized into interstate and state roads and averaged to obtain representative values for Florida conditions.
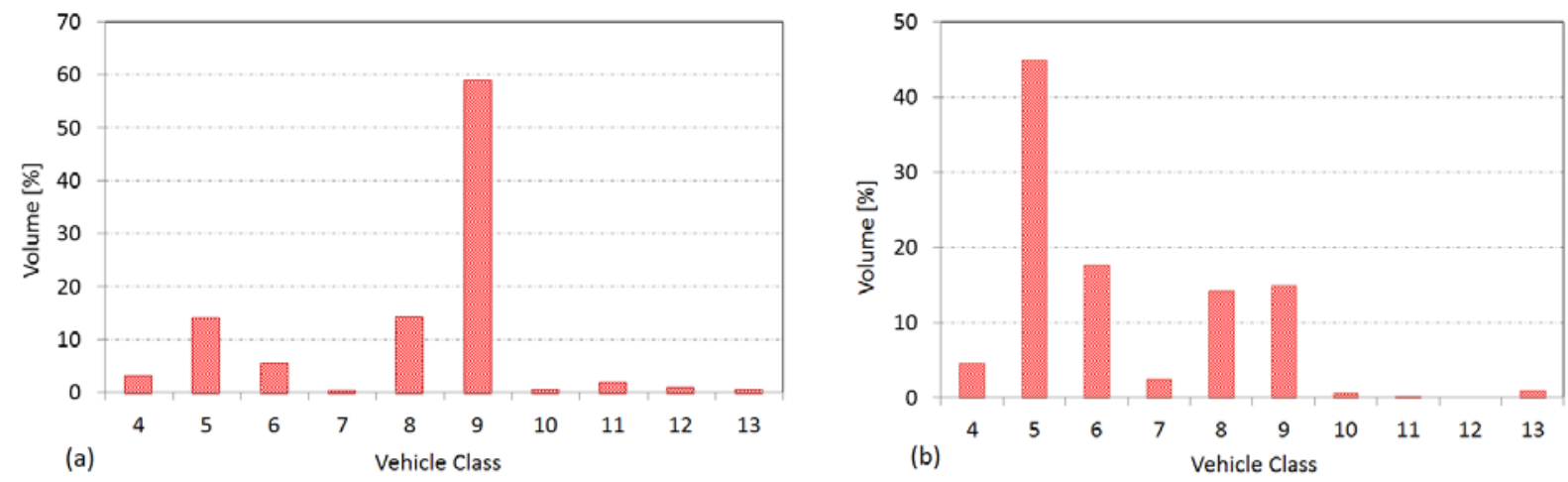

Figure 2. Representative vehicle class distribution factors for Florida interstate (a) and state (b) roads

\subsubsection{Interstate roads}

Data from nine WIM sites was used to obtain representative vehicle class distribution factors for Florida interstate roads. Figure 2 (a) illustrates the vehicle class distribution for Florida interstate roads and it can be seen that VC-9 is the most common vehicle type, which almost accounts $60 \%$ of the truck traffic. Many studies have also reported that vehicle class 9 is the most common vehicle type available on interstate roads (Hajek \& Selezneva, 2001; Jiang, Nantung \& Chen, 2008; Tran \& Hall, 2006; Wang \& Liu, 2000). 


\subsubsection{State roads}

Six WIM vehicle classification data was analyzed to establish the vehicle class composition of Florida state roads. As can been seen in Figure 2 (b), the dominant vehicle class type for Florida state roads is a five axles single trailer which is classified as VC-5 by FHWA classification. Buchanan (2004) has also observed that single-unit trucks were the primary type of trucks available on low volume routes in Mississippi.

\subsection{Axle load spectra}

Axle load spectra represent the magnitude and frequency of axle loads, which are one of the primary input parameters required for characterizing truck traffic for pavement performance evaluations in M-E methods (Lu \& Harvey 2006). The annual normalized load spectra for each axle configurations (Single, Tandem and Tridem) and vehicle class (VC 4-13) for Florida conditions were obtained by analyzing WIM data from LTPP and a study undertaken by Cunagin et al. (2013).

The LTPP database contains a five year average axle load spectra for each axle type and vehicle class. There was no consistent year to year difference among the years even if the data was observed to show substantial variations among the years. For this reason, the data of all the years were combined to generate average annual load spectra for the respective sites. Another set of data was obtained from Cunagin et al. (2013), which analyzed the Florida department of transportation database of truck weight data to develop a Level 2 axle load spectra for Florida conditions. A five year data from 2005 through 2009 which was monitored for quality during collection was used to generate representative average values for each WIM site. The data analysis of the axle load spectra has shown that there was less variation on yearly basis at a given WIM site while a substantial variation was observed among the various permanent WIM sites (Cunagin et al. 2013). For this study, a representative Level 3 axle load spectra for Florida conditions for each axle configuration and vehicle type was produced by averaging the data from the two sources. The developed load spectra for some of the vehicle classes and axle configurations (single, tandem and tridem) are illustrated in Figures 3, 4 (a) and 4(b).

Figure 3 presents vehicle classes 6, 8 and 9 single axle load spectra. As can be seen in the figure, the frequency distributions of the three vehicle classes follow a normal distribution and the load with the maximum frequency occurs for all the three cases in the load bins of 40-50 kN. In the case of tandem axle, as can be seen in Figure 4 (a), the frequency distributions for vehicle class 6, 8 and 9 can be best described with a bi-modal distribution. Figure 4 (b) presents the frequency distributions for vehicle classes 7, and 10 tridem axle configurations. As can be seen in the figure, the distribution of VC-7 might be explained and modeled with a normal distribution. 
In the case of VC-10 distribution, a lognormal distribution might fit the data. The tridem axle load spectra in contrast to single and tandem axle load spectra exhibit irregular distribution which might be due to the low number of vehicles that have tridem axle configuration in the overall traffic.

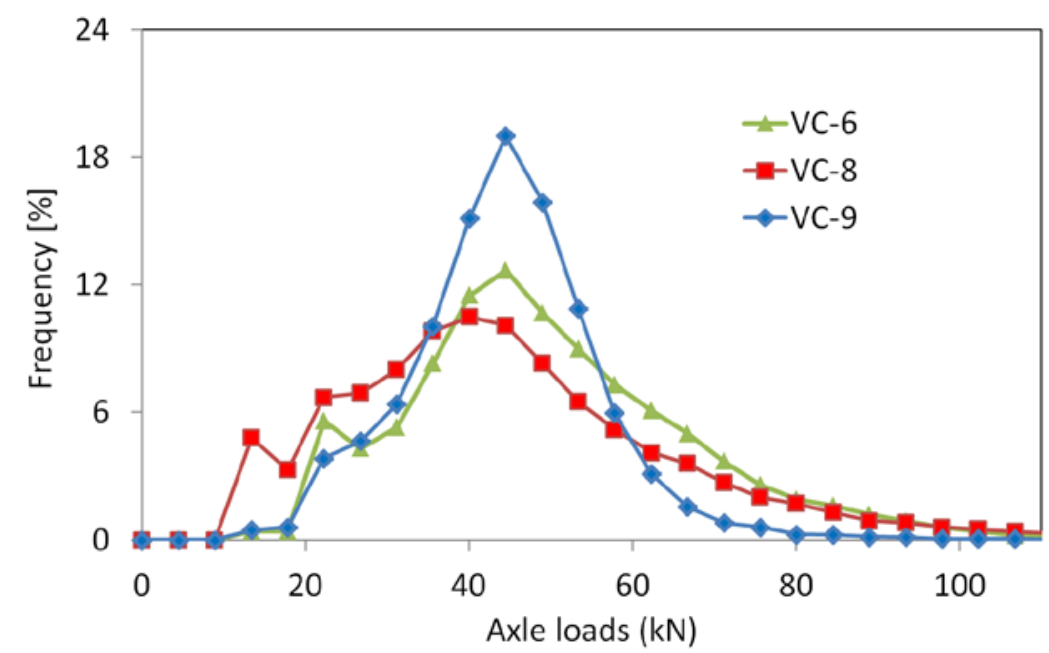

Figure 3. Representative single axle load spectra distributions for vehicle classes 6, 8 and 9
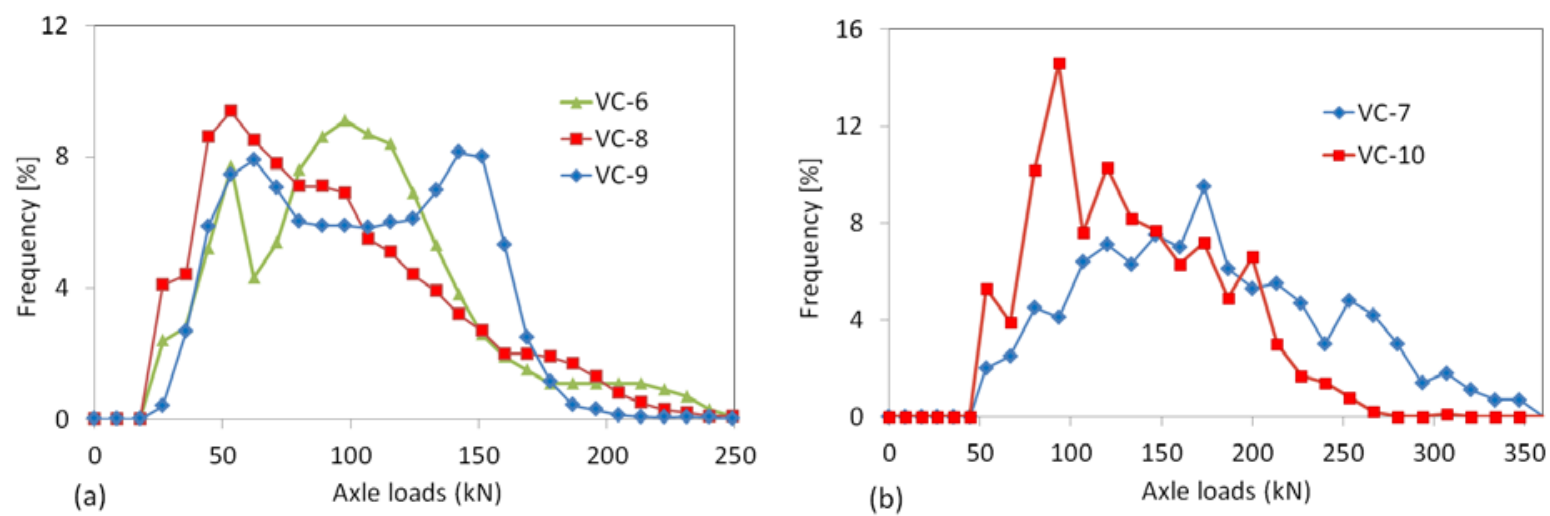

Figure 4. Representative tandem (a) and tridem (b) axle load spectra distributions for typical vehicle classes

\subsection{Seasonal traffic volume adjustment factors}

Most M-E pavement analysis and design procedures recommend factors such as monthly distribution factors (MDF) and hourly distribution factors (HDF) so as to adjust the average daily truck traffic volume. The mechanics-based analysis framework computes pavement response and damage accumulation on hourly basis and as such it is important to consider the effect monthly and hourly volume adjustment factors have on performance. WIM data from Cunagin et al. (2013) and Kwigizile (2004) were used respectively to generate representative monthly and hourly distribution factors for Florida conditions. 


\subsubsection{Monthly distribution factors}

Monthly distribution factors (MDF) represent the proportion of the annual truck traffic that occurs in a specific month. Monthly variations in truck traffic volume are site-specific and depend on factors such as the local economy and climate conditions (NCHRP, 1999). The Level 3 monthly distribution factors which are representative of Florida conditions were developed using data from Cunagin et al. (2013). Cunagin et al. (2013) studied the monthly average daily traffic of VC-9 for WIM site 9901 so as to determine the need for monthly based axle load spectra. As VC-9 is the most frequent vehicle class type on interstate roads, the MDFs for the mixed traffic stream can be determined using this data without losing significant accuracy. Figure 5 (a) presents the monthly distribution factors for Florida conditions. As can be seen in the figure the seasonal variation of the traffic does not follow a certain regular pattern, which might be due to the fact that few data points were used for generating the factors.

\subsubsection{Hourly distribution factors (HDF)}

The hourly distribution factors represent the expected percentage of the AADTT within each hour of the day. The Level 3 representatives HDF for Florida conditions was developed by studying and analyzing data from Kwigizile (2004). Hourly vehicular volume data from seven WIM sites were used for this purpose. Kwigizile (2004) collected three days of hourly vehicular volume data in a one month period which was later averaged to determine the HDFs of the studied highways. The WIM sites were located in different counties of Florida and the data at each WIM site was observed to exhibit less variation on daily basis but significant variation was observed among the various WIM sites. A representative HDFs for Florida conditions was developed by combining and averaging the data from the seven WIM sites. Figure 5 (b) presents the hourly distribution factors developed for Florida conditions.

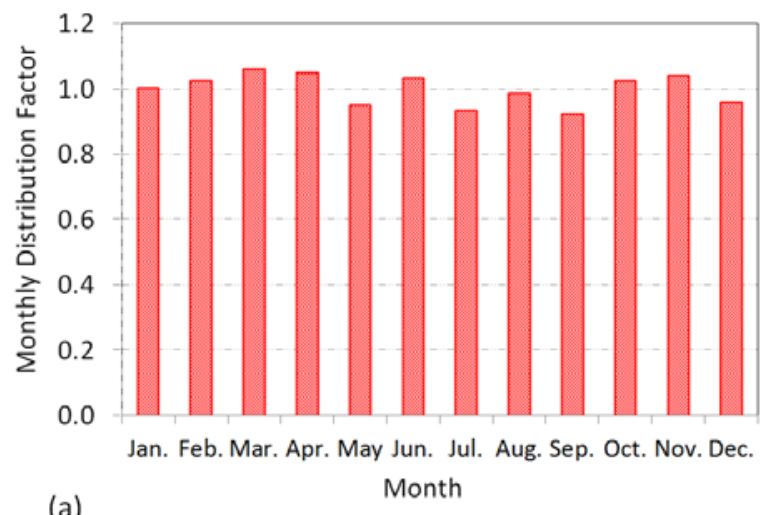

(a)

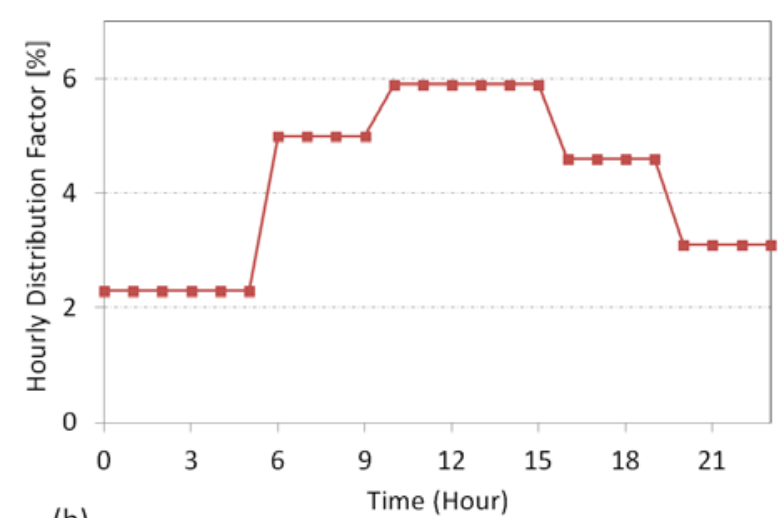

(b)

Figure 5. Representative monthly distributions factors (a) and hourly distribution factors (b) 


\subsection{Number of axles per truck}

The Number of Axles per Truck (NAPT) represents the average number of each axle configuration for each vehicle class (VC 4-13). For this study, the values recommended in the MEPDG for a Level 3 design were used (NCHRP, 1999). Table 1 presents the average suggested number of single, tandem and tridem axles for VC 4 to 13.

Table 1. Suggested number of axles per vehicle class

\begin{tabular}{lcccccccccc}
\hline Vehicle class & 4 & 5 & 6 & 7 & 8 & 9 & 10 & 11 & 12 & 13 \\
\hline Single & 1.62 & 2 & 1.02 & 1 & 2.38 & 1.13 & 1.19 & 4.29 & 3.52 & 2.15 \\
Tandem & 0.39 & 0.00 & 0.99 & 0.26 & 0.67 & 1.93 & 1.09 & 0.26 & 1.14 & 2.13 \\
Tridem & 0.00 & 0.00 & 0.00 & 0.83 & 0.00 & 0.00 & 0.89 & 0.06 & 0.06 & 0.35 \\
\hline
\end{tabular}

\section{Integrating axle load spectra into the mechanics based analysis framework}

As mentioned in the preceding section, the traffic characterization used in the mechanics-based analysis and design framework needs to be enhanced so as to reflect the current state of the practice in traffic characterization, and to improve the predictions accuracy. In the new traffic characterization, factors such as traffic growth rate, vehicle class distribution, axle load distributions, volume adjustment factors and lateral wheel wander need to be properly quantified and studied so as to establish the significance of each parameter.

A flowchart which depicts the integration process of axle load spectra and its associated parameters into the mechanics-based analysis framework is shown in Figure 6. This flowchart was developed using the mechanics-based analysis framework general outline which is presented in Figure 1. The main inputs which are required for pavement response computation and damage estimation are traffic, climate factors, asphalt mixture properties and structural information. As pavement response and damage accumulation are computed on hourly basis, inputs which show variations with time such as traffic and pavement temperature are required to be determined on hourly basis. More information regarding the inputs requirement and the material models can be obtained from Dinegdae et al. (2015)

For traffic loading characterization, the integration flowchart requires as an initial input the yearly AADTT of the whole analysis period. Each year AADTT is translated into monthly average daily truck traffic (MADTT) using MDFs, which reflect traffic seasonal variations. The MADTT is further adjusted using HDFs so as to obtain the monthly average hourly truck traffic (MAHTT), which is then distributed among vehicle classes 4 to 13 using traffic volume adjustment factors. For each vehicle class, the hourly axle load frequency of each axle configuration is obtained by multiplying MAHTT with the corresponding NAPT and normalized load frequency. For pavement response computation, the flowchart determines the load 
application point for successive axle loads through Monte Carlo simulation. For each hour, this process is repeated until all the hourly volume load effects are considered in the pavement response computation and damage accumulation and subsequently in pavement performance evaluation. The whole process is then performed for each hour and it ends when the accumulated damage equals the mixture threshold capacity, which signifies crack initiation.

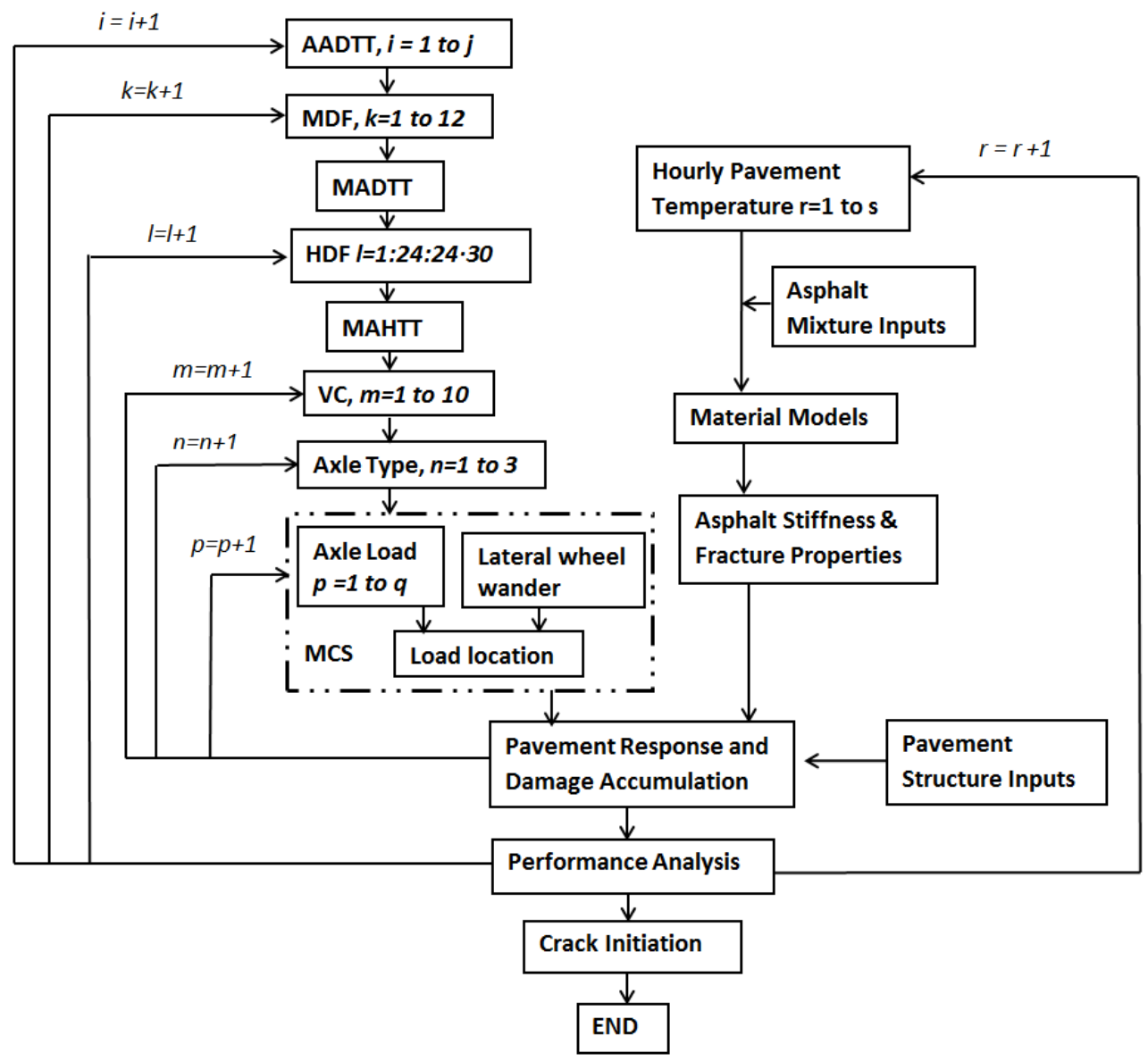

Figure 6. Flowchart for truck traffic integration into the mechanics-based analysis framework

The integration flowchart presented in Figure 6 was used to integrate and study the significance of traffic characterization inputs such as traffic growth rate, axle load spectra, lateral wheel wander and seasonal traffic variation on predicted top-down fatigue cracking performance. A detailed description of the traffic characterization inputs analyzed for this study is provided in the subsequent sections.

\subsection{ESALs with traffic growth}

The procedure recommended in the AASHTO-1993 design guide was followed to convert the mixed traffic stream into ESALs. AASHTO (1993) converts the various axle configurations and axle loads into ESALs using an empirically derived relation, which is based on the assumption 
that damage induced by two axle loads is related by a fourth power law (Huang, 2004). ESALs can be calculated either separately for each vehicle class or for the mixed traffic case, and needs information regarding the initial daily traffic in two directions over all lanes, percentage of trucks, directional and lane distribution factors. The AASHTO (1993) pavement design guide uses an 80 $\mathrm{kN}$ single axle configuration with a dual wheel, and the ESALs number for a given traffic is computed as follows:

$$
E S A L s=N \cdot \sum_{i=4}^{13} \sum_{j=1}^{3} \sum_{k=1}^{l} P_{i j k} \cdot E A L F_{j k}
$$

where ESALs are the total number of equivalent single axle loads for a given year in the analysis period. $N$ represents the average annual truck traffic of the design lane for a given analysis year. $P_{i j k}$ is the percentage of the $k^{\text {th }}$ axle load of the $j^{\text {th }}$ axle type $i^{\text {th }}$ vehicle class. $E A L F_{j k}$ is the equivalent axle load factor of the $k^{\text {th }}$ axle load of the $j^{\text {th }}$ axle type.

For this study, a typical expected traffic growth rate of $2.5 \%$ was assumed. The initial annual average daily truck traffic (AADTT) of every pavement section was determined through back calculation which uses the coring year ESALs and the traffic growth rate. The yearly ESALs traffic for the rest of the analysis period was obtained by using Equation 7.

\subsection{Axle load spectra}

The Level 3 axle load spectra for Florida conditions were used to establish the impact of truck traffic characterization in axle load spectra on fatigue cracking performance. Pavement response was computed by keeping the contact pressure constant, which is assumed to be equal to the tire inflation pressure, and varying the contact area with respect to the load. The assumption of constant contact pressure is a more realistic depiction of the actual traffic. As demonstrated by Morton, Luttig, Horak and Visser (2004), the tire inflation pressure for various axle loads is reasonably constant.

The use of axle load spectra for pavement response computations requires more time than the ESALs approach. In the case when the pavement response and damage accumulation is

performed on hourly basis as it is done in the mechanics-based analysis framework, this computational effort is expected to increase considerably. A design load spectra which simplifies the computational process while providing the same level of accuracy is required. For this purpose, a design single axle load spectra, which organizes the loads with $8 \mathrm{kN}$ interval, was developed. This was achieved by averaging the load bins and by aggregating the frequency distributions within each $8 \mathrm{kN}$ interval while taking into account the magnitude of each load effect through its respective EALF value. The principle of superposition was used to add the effects of the tandem and tridem axles into single axle so as to obtain a design single axle load spectra. It is apparent that using a simplified single axle load spectra to represent the entire load spectra would introduce a certain magnitude of error into the analysis but considering the fact that this is a Level 
3 analysis where many simplified assumptions are used in material characterization and material behaviour this approach can be accepted.

\subsection{Axle load spectra with lateral traffic wander}

In this characterization, the effect of lateral traffic wander on fatigue cracking performance was studied. For this study, the variability of the lateral wheel wander was modeled with a normal distribution with a standard deviation of 25.4 centimeters (NCHRP, 1999). The performance analysis was performed by following the same procedure as the load spectra characterization while Monte Carlo based simulation was used to determine the location of each subsequent load application.

\subsection{Axle load spectra with volume adjustment factors}

In this section, the effect of truck traffic volume adjustment factors on fatigue cracking performance was evaluated. The monthly and hourly volume adjustment factors for Florida conditions were used to incorporate seasonal and hourly traffic variations into the analysis framework. The introduction of volume adjustment factors into the axle load spectra characterization is expected to increase the required computational efforts further. The same procedure as the load spectra characterization was followed to obtain pavement response while damage is computed by applying the adjusted hourly traffic volume of each load bins of the respective axle load distributions.

Table 2. Information about the field pavement sections used in this study

\begin{tabular}{llcccc}
\hline \multicolumn{1}{c}{ Section } & \multicolumn{1}{c}{ County } & $\begin{array}{c}\text { Observed } \\
\text { CI }\end{array}$ & $\begin{array}{c}\text { Predicted } \\
\text { CI }\end{array}$ & $\begin{array}{c}\text { Traffic / year } \\
\left(10^{3} \text { ESALs }\right)\end{array}$ & $\begin{array}{c}\text { Functional } \\
\text { Classification }\end{array}$ \\
\hline I75-1A & Charlotte & 10 & 11.2 & 573 & Interstate \\
I75-1B & Charlotte & 11 & 10.3 & 558 & Interstate \\
I75-3 & Lee & 11 & 13.1 & 674 & Interstate \\
SR80-1 & Lee & 14 & 10.3 & 221 & State road \\
SR80-2 & Lee & 15 & 15.6 & 207 & State road \\
I-10EB & Duval & 13 & 10.0 & 1010 & Interstate \\
US-301SB & Marion & 11 & 11.0 & 510 & Interstate \\
\hline
\end{tabular}

\section{Results and discussion}

\subsection{Pavement sections}

A number of field pavement sections from Florida were analyzed using the mechanics-based analysis framework so as to quantify and establish the significance of the various traffic characterization parameters. A total of 7 pavement sections, that have high quality laboratory and field performance data and a wide range in design inputs, were selected for this purpose. These are the same sections used by Dinegdae et al. (2015) to calibrate the mechanics-based analysis 
framework. The sections are comprised of state roads and interstate highways. The existence of various design features in the pavement sections would provide a good opportunity to identify those traffic characterization parameters that might have a significant effect on predicted performance. Table 2 provides information regarding location, traffic volume, observed and predicted crack initiation times of these sections. Further information regarding asphalt mixture properties, pavement structure and environmental factors can be obtained from Dinegdae et al. (2015).

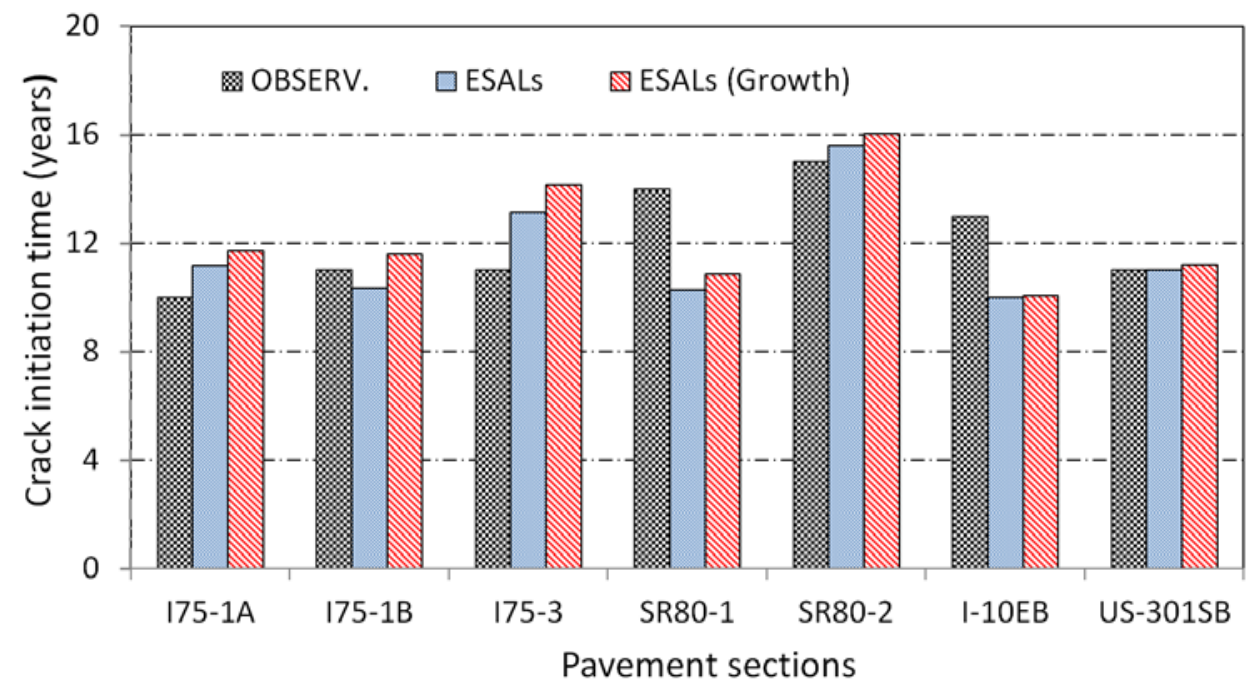

Figure 7. Impact of ESALs with traffic growth (ESALs, growth) on predicted fatigue cracking performance

\subsection{Impact of traffic growth rate}

The effect of truck traffic growth rate on predicted crack initiation time was evaluated using the 7 pavement sections listed in Table 2. The predictions from ESALs without truck traffic growth rate were used as a reference for comparison purpose. The predicted results for the two characterizations are compared in Figure 7. As can be seen in the figure, for all the studied sections, the ESALs with truck traffic growth rate characterization induces less damage and thus resulted in later crack initiation times. This increase in fatigue life could be explained by the fact that the coring year for most of the sections was around 10-15 years. Thus, the inclusion of traffic growth rate on the traffic estimation would decrease early year's traffic volume, which results in less damage and later crack initiation time. The analysis of the result has shown that traffic growth rate would increase on average the crack initiation time by $5 \%$, and for some pavement sections this increment can reach $10 \%$. Even if there is some difference between the two predictions, the one way analysis of variance (ANOVA) result has shown that there is no statistically significant difference between the two predictions. The figure also shows that the increase in fatigue life is not uniform for all the sections, which indicates the complex 
interactions that exist between the various design inputs used to define and predict top-down fatigue cracking.

\subsection{Impact of axle load spectra}

The impact of traffic characterization in axle load spectra on pavements fatigue cracking performance was studied by analyzing the performance of the 7 pavement sections listed in Table 2 using the Level 3 axle load spectra for Florida conditions. The predictions for the ESALs characterization with truck traffic growth rate were selected as a reference for comparison. Figure 8 compares the crack initiation times of the studied pavement sections for the two characterizations. For all the sections studied, the load spectra characterization resulted in early crack initiation times. Ahmed and Erlingsson (2014) and Zhao, Tan and Zhou (2012) have also reported that axle load spectra characterization of truck traffic induces more damage than the ESALs approach. A study by Zhao et al. (2012) observed that top-down fatigue cracking to be more sensitive to axle load spectra characterization than bottom-up fatigue cracking or rutting.

A closer look at the results in Figure7 shows that for some pavement sections the ESALs characterization delivers better approximation to the observed performance than the axle load spectra characterization, this might be explained by the fact that the mechanics-based analysis framework was originally calibrated using the ESALs approach. The two predictions were compared using the normalized error approach and it was found that the average normalized prediction error between the two characterizations is $11 \%$ and for some sections this normalized error reaches almost 20\%. Nevertheless, the one way ANOVA analysis has shown that there is no statistically significant difference between the two predictions.

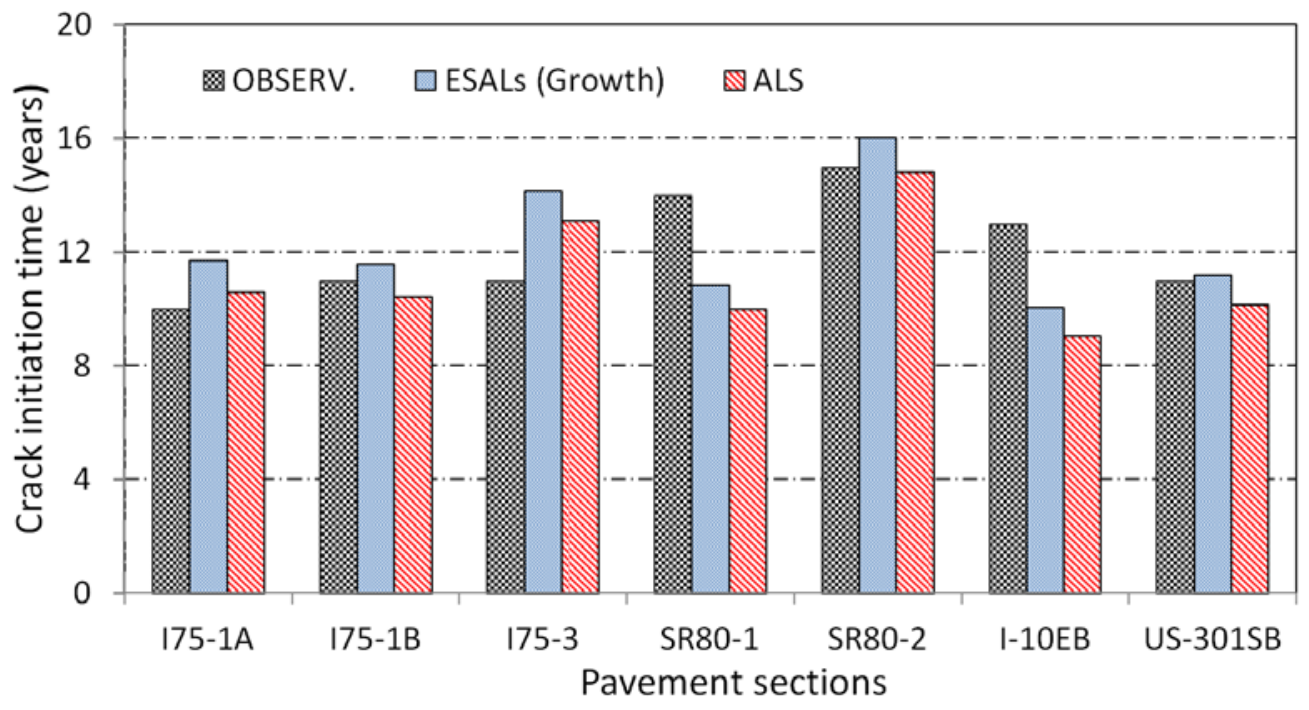

Figure 8. Impact of axle load spectra (ALS) on predicted fatigue cracking performance 


\subsection{Impact of lateral wheel wander}

In this analysis, the impact of lateral wheel wander on predicted fatigue cracking performance was evaluated. Monte Carlo simulation was used to incorporate lateral wheel wander effect into the axle load spectra characterization. Monte Carlo simulation, based on the underlying variability of the truck wheel wander, generates a unique load location for every consecutive load application. Figure 9 presents the generated lateral wheel wander distribution for the pavement section Charlotte I75-1A. A chi-squared goodness of test has shown that the generated lateral wheel wander can be considered to follow a normal distribution. As can be seen in the figure, most of the wheel applications, almost $90 \%$, occur in a distance of $25.4 \mathrm{~cm}$ from the mean in both directions.

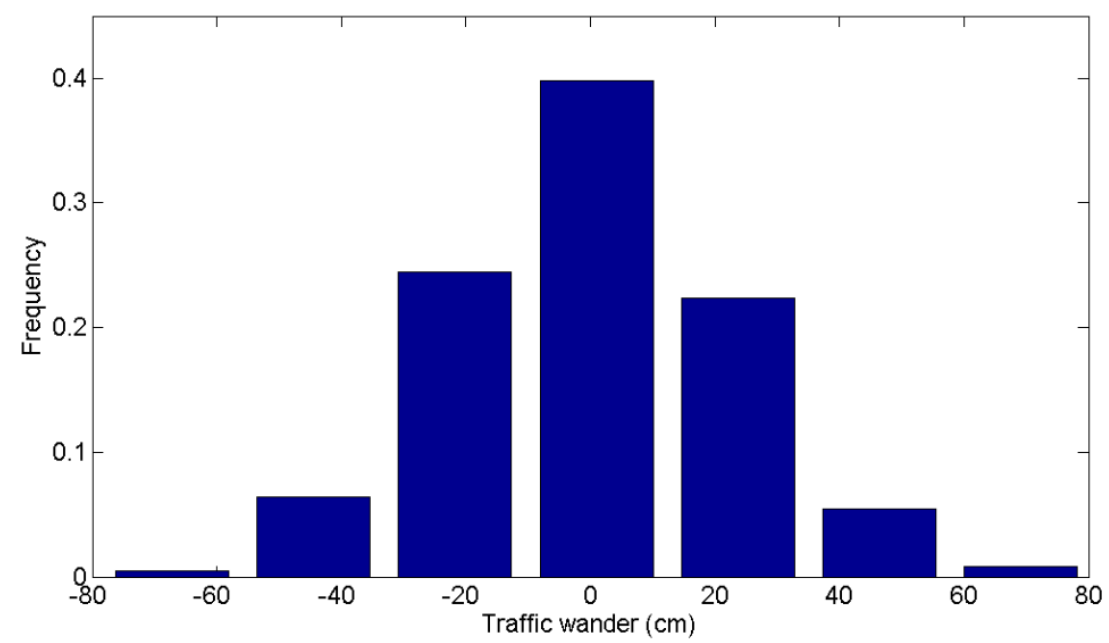

Figure 9. Monte Carlo generated traffic wheel wander frequency distributions

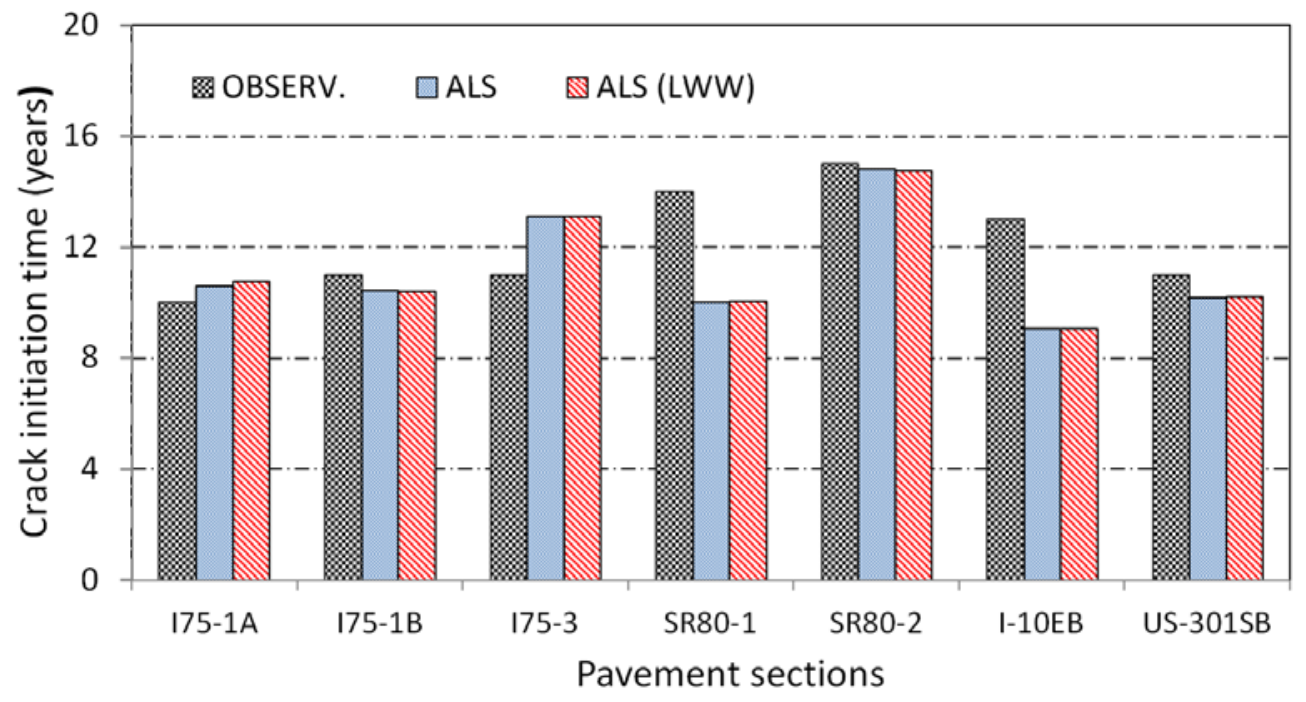

Figure 10. Impact of axle load spectra with lateral wheel wander (ALS, LWW) on predicted fatigue cracking performance5.5 Impact of volume adjustment factors 
Figure 10 compares the predicted results for axle load spectra with and without truck wheel wander. It is obvious from Figure 10 that the difference in the predictions between the two characterizations is negligible. The normalized error between the two predictions is $1 \%$, which is insignificant and might imply that the effect of lateral wheel wander can be ignored in the mechanics-based analysis framework. The one way ANOVA have shown also that there is no statistically significant difference between the predictions and the observed values. The predicted results for axle load spectra with lateral wheel wander might seem counter-intuitive, but in the mechanics-based analysis framework the maximum tensile stress on the surface of the asphalt concrete layer is searched on a wider area and changing the load application point might not have that much impact on the magnitude of the maximum stress.

\subsection{Impact of volume adjustment factors}

In this section, the impact of volume adjustment factors on predicted fatigue cracking performance was analyzed. The predictions from the load spectra without volume adjustment factors characterization were used as a reference for comparison purpose. The effect of lateral wheel wander was ignored in both characterizations as it has been found to have negligible impact on predicted performance. Figure 11 compares the predictions from the two characterizations. As can be seen in Figure 11, considering traffic volume adjustment factors in axle load spectra characterizations induces more damage and results in early crack formation. However, the one way ANOVA result has shown that there is no statistically significant difference among the observed and predicted values.

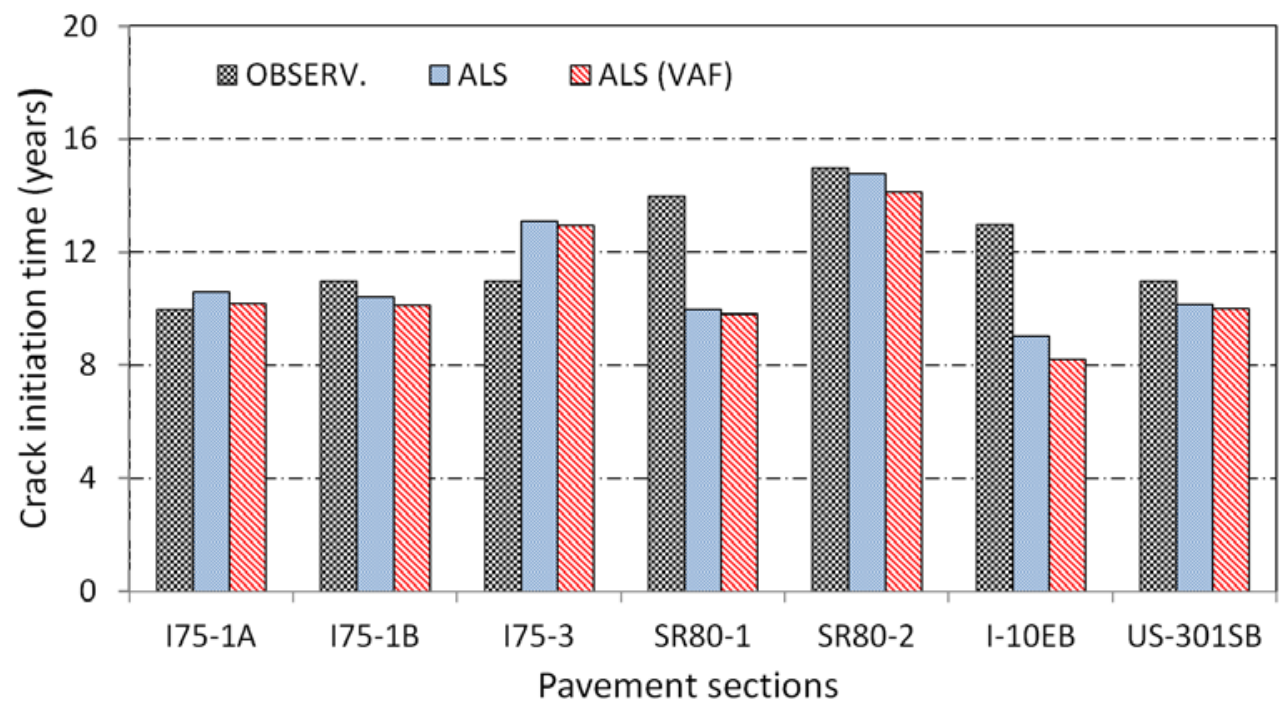

Figure 11. Impact of axle load spectra (ALS) with volume adjustment factors (VAF) on predicted fatigue cracking performance 


\section{Conclusions and recommendations}

This paper integrated axle load spectra and its associated parameters into the mechanics-based analysis framework and established theirs impact on asphalt concrete fatigue cracking performance by evaluating a number of field pavement sections. An approach and a flowchart for the integration of axle load spectra and its associated parameters into the mechanics-based analysis framework were proposed and traffic characterization inputs such as axle load spectra, vehicle class distributions, volume adjustment factors and lateral wheel wander which are representative of Florida conditions were also developed. The predicted results for the various traffic characterization parameters have shown clearly that the database used to develop the representative traffic characterization inputs was sufficient enough in providing acceptable results.

From the analysis, it can be observed that traffic characterization in axle load spectra has the highest influence on predicted fatigue cracking performance. ESALs with traffic growth and axle load spectra with volume adjustment factors also have been observed to influence predicted performance relatively while the influence from lateral wheel wander is insignificant. The integrated Monte Carlo simulation has successfully generated a load application point for successive traffic loads which is in agreement with the statistical information of the traffic lateral wheel wander. For practical purpose, the use of ESALs is acceptable as it has been found, for some pavement sections, in delivering better approximation to the observed field performance than the axle load spectra characterization.

The database which was used for developing the traffic characterization inputs needs to be extended so as to reflect the state-wide traffic variations, and to more accurately capture the significance of these parameters influence on predicted fatigue cracking performance. A further analysis including seasonal climate change effect on unbound granular layers and subgrade properties might be necessary to fully assess and understand the impact of volume adjustment factors on predicted fatigue cracking performance. As its influence on predicted cracking performance is negligible, truck wheel wander effect could be ignored in axle load spectra characterizations. Moreover, a recalibration of the mechanics-based analysis framework using the axle load spectra approach is necessary in order to capture accurately the impact axle load spectra and its associated parameters have on top-down fatigue cracking performance.

\section{Acknowledgements}

The authors would like to thank the Swedish transport administration Trafikverket and the Swedish construction industry organization for research and development SBUF for providing the financial support for the project under which this work was performed. 


\section{References}

1. AASHO, 1962. Special Report 61-E: The American Association of State Highway Officials Road Test, Report 5: Pavement Research. TRB, National Research Council, Washington, D.C.

2. AASHTO, 1972. AASHTO Interim Guide for Design of Pavement Structures, American Association of State Highway and Transportation Officials, Washington, D.C.

3. AASHTO, 1993. Guide for Design of Pavement Structures, American Association of State Highway and Transportation Officials, Washington, D.C.

4. Ahmed, A. W., \& Erlingsson S., (2014). Characterization of heavy traffic axle load spectra for mechanistic-empirical pavement design applications, International Journal of Pavement Engineering, V 16, 6 pp. 488-501

5. Birgisson, B., Wang, J., \& Roque, R. 2006. Implementation of the Florida cracking model into the mechanistic empirical pavement design. Gainesville, University of Florida

6. Buchanan, M. S., 2004. Traffic Load Spectra Development for the 2002 AASHTO Pavement Design Guide. Mississippi Department of Transportation, FHWA/MS-DOT-RD-04-165, Mississippi State University.

7. Button, J. W., D. N. Little, Y. Kim, \& Ahmed, J., 1987. Mechanistic evaluation of selected asphalt additives. Journal of the Assosiation of Asphalt Paving Technologists, 56, 62-90

8. Cunagin, W., Reel, R. L., Ghanim, M. S., Roark, D., and Leggett, M., 2013. Generating SiteSpecific Axle Load Factors for the Mechanistic-Empirical Pavement Design Guide. In Transportation Research Record: Journal of the Transportation Research Board No. 2339. Transportation Research Board of the National Academies, Washington D.C., pp. 98-103

9. Daniel, J. S., \& Kim, Y. R., 2001. Laboratory evaluation of fatigue damage and healing of asphalt mixtures. ASCE Journal of Materials in Civil Engineering, 13(6), 434-440

10. Dinegdae, Y.H., and Birgisson, B., 2015. Reliability-based calibration for a mechanics-based fatigue cracking design procedure. Journal of Road Materials and Pavement Design. V 17, 3 pp. 529-546

11. Dinegdae, Y.H., Onifade, I., Jelagin, D and Birgisson, B., 2015. Mechanics-based top down fatigue cracking initiation prediction design framework for asphalt pavements. Journal of Road Materials and Pavement Design. V 16, 4 pp. 907-927

12. FHWA, 2001. Traffic Monitoring Guide, Office of Highway Policy Information, Federal Highway Administration, U.S. Department of Transportation

13. Hajek, J. J, 1995. General Axle Load Equivalency Factors. In Transportation Research Record 1482, TRB, National Research Council, Washington, D.C., pp. 67-78.

14. Hajek, J.J., and Selezneva, O.I., 2001. New Developments in the Use of Traffic Data for Pavement Management. Proceedings of the 5th International Conference on Managing Pavements, ISBN number- 0971174016, August 11-14, 2001, Seattle, Washington

15. Huang, Y.H., 2004. Pavement analysis and design. Upper Saddle River, New Jersey: Pearson Prentice Hall. 
16. Jiang, Y., Li, S., Nantung, T. E., and Chen, H., 2008. Analysis and Determination of Axle Load Spectra and Traffic Input for the Mechanistic-Empirical Pavement Design Guide. Publication FHWA/IN/ JTRP-2008/07. Indiana department of transportation and Purdue University, West Lafayette, Indiana

17. Kwigizile, V., 2004. Connectionist Approach to Developing Highway Vehicle Classification Table for Use in Florida. Thesis (Masters), DigiNole Commons, the Florida State University

18. Kumar Das, P., Birgisson, B., Jelagin, D., \& Kringos, N., 2015. Investigation of the asphalt mixture morphology influence on its aging susceptibility. Materials and Structures, V. 48, 4 pp. $987-1000$

19. Lira, B., Jelagin, D., \& Birgisson, B., 2013. Gradation-based framework for asphalt mixture. Materials and structures, V. 46, 8, pp. 1401-1414

20. Lu, Q., and Harvey, J. T., 2006. Characterization of truck traffic in California for mechanistic empirical design. Washington, DC: Transport Research Board.

21. Mirza, M. W., \& Witczak, M. W. (1995). Development of a global aging system for short and long term aging of asphalt cements. Journal of the Association of Asphalt Paving Technologists, 64, 393-430

22. Morton, B. S., Luttig, E., Horak, E., and Visser, A. T., 2004. The effect of axle load spectra and tyre inflation pressures on standard pavement design methods. Proceedings of the $8^{\text {th }}$ Conference in Asphalt Pavements for Southern Africa (CAPSA'04), ISBN number: 1-92001718-6. 12-16 Sept. 2004, Sun City, South Africa.

23. MnPAVE, 2005. Minnesota Mechanistic-Empirical Pavement Design. Homepage, Minnesota Department of Transportation. http://www.mrr.dot.state. mn.us/research/mnpave/mnpave.asp. Accessed July 11, 2005.

24. NCHRP, 1999. Guide for Mechanistic-Empirical design of new and rehabilitated pavement structures. Final document, Appendix AA: traffic loading, ERES Consultants Division, ARA Incorporation, Washington D.C.

25. NCHRP 1-37A, 2004. Guide for Mechanistic-Empirical Design of New and Rehabilitated Pavement Structures, Final Report, ERES Consultants Division, ARA Incorporation, Washington D.C.

26. NCHRP Web-Only Document 162, 2010 .Top-down cracking of hot-mix asphalt layers: Models for 5 initiation and propagation. Washington, DC: National Cooperative Highway Research Program, 6 Transportation Research Board

27. Rauhut, J. B., Lytton, R. L., and Darter, M. I., 1984. Pavement Damage Functions for Cost. Allocation, Vol. 1. Damage Functions and Load Equivalence Factors. Report FHWA/RD84/018. FHWA, U.S. Department of Transportation.

28. Roque, R., Birgisson, B., Sangpetngam, B., \& Zhang, Z. (2002). Hot mix asphalt fracture mechanics: A fundamental crack growth law for asphalt mixtures. Journal of the Association of Asphalt Paving Technologists, 71, 816-827

29. Swan, D.J., Tardif, R., Hajek, J., \& Hein, D.K., 2008. Development of regional traffic data for the mechanistic-empirical pavement design guide. Transportation Research Record, No. 2049) (pp. 54-62). Washington, DC: Transportation Research Board. 
30. Timm, D. H., and Young, J., 2004. The Effects of Load Spectra and Variability on Perpetual Pavement Design. Proc., International Symposium on Design and Construction of Long Lasting Asphalt Pavements, International Society for Asphalt Pavements, Auburn, Ala., pp. 131-152.

31. Tran, N. H., and Hall, K. D., 2006. Projected Traffic Loading for Mechanistic- Empirical Pavement Design Guide. Draft final report, University of Arkansas, Fayetteville.

32. Viljoen, A. W. (2001). Estimating Asphalt temperatures from air temperatures and basic sky parameters. Internal report, Transportek, CSIR, Pretoria.

33. Wang, T., and Liu, C., 2000. Influence of heavy trucks on highway bridges. Final report, Research report No. FL/DOT/RMC/6672-379, Florida department of transportation, Tallahassee, Florida

34. Wang, J., Birgisson, B., and Roque, R., 2007. Windows-Based Top-Down Cracking Design Tool for Florida. In Transportation Research Record: Journal of the Transportation Research Board, No. 2037. Transportation Research Board of the National Academies, Washington, DC, pp. 86-96.

35. Witczak, M. W., \& Fonseca, O. A. (1996). Revised predictive model for dynamic (complex) modulus of asphalt mixtures. Transportation Research Record, 1540, 15-23

36. Yideti, T. F., Birgisson, B., Jelagin, D., \& Guarin, A., 2013. Packing theory-based framework for evaluating the resilient modulus of unbound granular materials. International Journal of Pavement Engineering, V.15, 8, pp. 689-697

37. Zhao, Y., Tan, Y., and Zhou, C., 2013. Determination of axle load spectra based on percentage of overloaded trucks for mechanistic-empirical pavement design. Journal of Road Materials and Pavement design V.13, 14, pp. 850-86 